\title{
Severe bereavement stress during the prenatal and childhood periods and risk of psychosis in later life: population based cohort study
}

\author{
() (1) $\Theta$ OPEN ACCESS
}

\author{
K M Abel professor ${ }^{1}, \mathrm{H}$ P Heuvelman doctoral student ${ }^{12}$, L Jörgensen research associate ${ }^{3}, \mathrm{C}$ \\ Magnusson professor ${ }^{3}$, S Wicks postdoctoral research associate ${ }^{3}$, E Susser professor ${ }^{4}$, J Hallkvist \\ postdoctoral research assistant ${ }^{35}$, C Dalman associate professor ${ }^{3}$
}

${ }^{1}$ Centre for Women's Mental Health, Manchester Academic Health Sciences Centre, Institute of Brain Behaviour and Mental Health, University of Manchester, Manchester, UK; ${ }^{2}$ The Cathie Marsh Centre for Census and Survey Research, University of Manchester, Manchester, UK; ${ }^{3}$ Division of Public Health Epidemiology, Department of Public Health Sciences, Karolinska Institutet, Stockholm, Sweden; ${ }^{4}$ Imprints Center for Genetic and Environmental Life Course Studies, Mailman School of Public Health and New York State Psychiatric Institute, Columbia University, NY City, NY, USA; ${ }^{5}$ Department of Public Health and Caring Sciences, Uppsala University, Uppsala, Sweden

\begin{abstract}
Objective To examine the risk of psychosis associated with severe bereavement stress during the antenatal and postnatal period, between conception to adolescence, and with different causes of death.

Design Population based cohort study.

Setting Swedish national registers including births between 1973 and 1985 and followed-up to 2006.

Participants In a cohort of 1045336 Swedish births (1973-85), offspring born to mothers exposed to severe maternal bereavement stress six months before conception or during pregnancy, or exposed to loss of a close family member subsequently from birth to 13 years of age were followed until 2006. Admissions were identified by linkage to national patient registers.
\end{abstract}

Main outcome measures Crude and adjusted odds ratios for all psychosis, non-affective psychosis, and affective psychosis.

Results Maternal bereavement stress occurring preconception or during the prenatal period was not associated with a significant excess risk of psychosis in offspring (adjusted odds ratio, preconception 1.24, 95\% confidence interval 0.96 to 1.62 ; first trimester $0.95,0.58$ to1.56; second trimester $0.79,0.46$ to 1.33 ; third trimester $1.14,0.78$ to 1.66$)$. Risks increased modestly after exposure to the loss of a close family member from birth to adolescence for all psychoses (adjusted odds ratio 1.17, 1.04 to 1.32 ). The pattern of risk was generally similar for non-affective and affective psychosis. Thus estimates were higher after death in the nuclear compared with extended family but remained non-significant for prenatal exposure; the earlier the exposure to death in the nuclear family occurred in childhood (all psychoses: adjusted odds ratio, birth to 2.9 years $1.84,1.41$ to $2.41 ; 3-6.9$ years $1.47,1.16$ to $1.85 ; 7-12.9$ years $1.32,1.10$ to 1.58 ) and after suicide. Following suicide, risks were especially higher for affective psychosis (birth to 2.9 years $3.33,2.00$ to $5.56 ; 6.9$ years $1.84,1.04$ to $3.25 ; 7-12.9$ years $2.68,1.84$ to 3.92 ). Adjustment for key confounders attenuated but did not explain associations with risk.

Conclusions Postnatal but not prenatal bereavement stress in mothers is associated with an increased risk of psychosis in offspring. Risks are especially high for affective psychosis after suicide in the nuclear family, an effect that is not explained by family psychiatric history. Future studies are needed to understand possible sources of risk and resilience so that structures can be put in place to support vulnerable children and their families.

\section{Introduction}

Epidemiological studies in humans ${ }^{1}$ and genetic investigations in other species ${ }^{2}$ have led to the hypothesis that risk of disease in adulthood can be influenced not only by genotype and lifestyle in adulthood but also by early environmental experience. In a world where many women of reproductive age remain exposed to unquantifiable violence, ${ }^{3}$ evidence that maternal psychological stress adversely affects the developmental trajectory of the fetus has important implications for both public health and mental health.

Evidence for an association between early maternal stress and some perinatal $^{4-7}$ as well as specific cognitive and brain 
developmental outcomes ${ }^{8-10}$ in offspring is relatively robust, but thus far population studies provide relatively weak support for an association between maternal psychological stress during the prenatal period and later psychosis. The larger population studies examining ecological exposures to environmental stressors, such as war, ${ }^{11-13}$, radiation, ${ }^{14}$ or other natural disasters, ${ }^{15}$ as well as smaller studies examining exposure to psychological stress at the individual level, ${ }^{16-19}$ have encouraged the view that prenatal psychological stress is in part responsible for increasing the risk of severe mental illness in a population. In addition, many animal experiments have begun to explore mechanistic models of prenatal stress and neurodevelopmental outcomes. ${ }^{4} 19$ However, the definition of a mother's exposure to stress and the timing of the exposure in ecological studies may be inexact. The most convincing and methodologically strongest studies to date have been population studies utilising individual level data by examining the effect of deaths occurring in the antenatal period in both the nuclear and the extended family. ${ }^{20-22}$ Death as an exposure is clearly defined and timed and can be linked easily to individuals; two Danish population studies report significant effects on risk of schizophrenia ${ }^{20}$ and affective disorder ${ }^{21}$ after bereavement in the antenatal period. Exposed cases were, however, too few to assess bipolar disorder, ${ }^{21}$ and effects were confined to 16 exposed cases of schizophrenia and only those without a family history. Other researchers ${ }^{22}$ have carried out the largest, most recent study to date using exposures to bereavement stressors. They reported no effect of maternal exposure to bereavement in the antenatal period or during the first two years of childhood on subsequent risk of schizophrenia, non-affective psychosis, or bipolar disorder. In this study, most of the exposures experienced by mothers and offspring were deaths of maternal grandparents or maternal siblings (aunts and uncles of index offspring), the "extended" family. Although death represents both clearly defined and individual level data as an exposure to psychological stress, its measurement has other limitations. Firstly, death is a relatively rare event. Combined with the relative rarity of psychosis as an outcome, this often provides for limited power, even in large samples. ${ }^{20} 21$ Secondly, deaths may be clearly timed from mortality data, but their effects may depend on both the proximity to the mother of the individual who dies as well as the expectedness of the death: deaths from sudden incidents or suicide, particularly in the nuclear family, are likely to be more stressful and their effects longer lasting than deaths of elderly relatives from prolonged illness. Thirdly, deaths are not randomly distributed in the population and, therefore, are not a perfect "natural experiment" in which to study the effects of psychosocial stress. For example, in younger age groups (nuclear family) deaths are more likely to be due to suicides and thus related to psychiatric disorders $(90 \%$ of people who commit suicide have psychiatric disorders). ${ }^{23}$ A significant proportion of deaths in parents during early middle age are from suicide; apart from the parental loss constituting a highly stressful event, this may also indicate a genetic predisposition to psychiatric illness. ${ }^{24}$ No studies to date have examined the risk associated with cause of death, such as suicide or a fatal accident. Finally, parental loss during childhood has been extensively studied in relation to subsequent depression but only sparsely in relation to psychosis, ${ }^{22} 25-27$ and risk of loss in early adolescence has largely not been examined. This is likely to be of particular relevance when considering more distal outcomes such as psychoses.

We re-examined support for the association between deaths in the family and psychosis in later life. In particular, we examined associations between causes of death. Specifically, we evaluated whether risk of psychosis associated with death of a first degree relative is greater if death occurs during the antenatal period compared with during childhood; whether risk is greater for non-affective compared with affective psychoses; whether risk is greater after death in the nuclear family (biological parent or older sibling of the child) compared with the extended family (grandparents); and finally whether risk is greatest after sudden death by an accident or suicide compared with natural causes.

\section{Methods}

This cohort study was based on data from the national registers held by Statistics Sweden and the Swedish National Board of Health and Welfare. We carried out register linkage using the unique personal identification number assigned to each Swedish citizen at birth or to immigrants on arrival in Sweden. These numbers are recorded in all contacts with healthcare, social, and administrative services, enabling complete and accurate data linkage between registers. We identified all children born alive in Sweden between 1 October 1973 and 31 December 1985 $(n=1151883)$.

\section{Case ascertainment}

We defined diagnostic groups as "at least once or never admitted to hospital for the particular diagnosis" obtained through linkage to the National Patient Register 1973-2006, which provides a primary and contributing diagnosis on all psychiatric inpatient visits since 1973 using the international classification of diseases, 8th, 9th, and 10th revisions. Definitions of psychosis were: non-affective psychosis (ICD-10: F25; ICD-9: 295H; ICD-8: 295.70), including schizophrenia and related and other non-organic psychoses (ICD-10: F20-29; ICD-9: 295A-295G, 295W-295X, 297A-297X, 298C-298X; ICD-8: 295.00-295.60, 295.80, 295.99, 297.00-297.98, 298.20-298.99, 299.99), and affective psychosis (identified as bipolar disorder with psychosis and unipolar depression with psychosis) (ICD-10: F31, F30.2, F32.3, F33.3; ICD-9: 296C-296W; ICD-8: 296.10-296.88). A broad diagnostic category named "all psychoses" included ICD-10: F20-F29, F31, F30.2, F32.3, F33.3; ICD-9: 295A-295X, 296C-296W, 297A-297X, 298C-298X; and ICD-8: 295.00-295.99, 296.10-296.88, 297.00-297.98, 298.20-298.99, 299.99.

\section{Exposure}

We defined exposure in the mother to bereavement stress preconception or during the prenatal period as death of her biological parents, her offspring, or the biological father of the offspring. A mother was considered exposed if at least one of these relatives died during the window of exposure, regardless of links to other relatives. Thus, during the antenatal period or six months preconception, the death of a mother's relative created exposure, but, in the postnatal period, offspring could also be considered exposed to the death of their own mother. We further subdivided deaths into nuclear family deaths: the mother's spouse or another child (antenatally); during the postnatal period, the nuclear family could also include the mother herself, as well as the biological father and siblings of the index offspring. In the extended family, we defined deaths as those occurring in the mother's parents or index offspring's maternal grandparents. Unexposed mothers or offspring were those who had links to all relatives and who had no event during the exposure period. We obtained links to relatives through the multigenerational register, Statistics Sweden. We divided exposure periods into: any exposure (all exposures in the prenatal and postnatal periods), any prenatal exposure (preconception to birth), and any postnatal exposure (birth to 
13 years). We further divided exposure periods into preconception (6-0 months before conception) and by trimester (first, 0-12 weeks; second, 13-24 weeks; and third, 25 weeks to birth); and by postnatal period (0-2.9 years; $3-6.9$ years; and 7-12.9 years; table $1 \Downarrow)$. The timing was calculated using information on gestational age from the medical birth register. If more than one exposure occurred during the study period, we gave priority to the earliest exposure - that is, the first trimester, preconception, second trimester, third trimester, and the three postnatal periods. We ascertained cause of death from the cause of death register and further divided this into three subcategories: suicide, fatal injury or accident, and other, among which cancers and cardiac events were the most common (see supplementary table for all E codes). As a delay could occur between onset of psychosis and ascertainment by the registry, we also excluded those exposed to loss between ages 13-20 years. This ensured that the outcome (psychosis) always came after the exposure.

\section{Statistical analyses}

Using logistic regression, we estimated crude and adjusted odds ratios, with $95 \%$ confidence intervals. We used the STATA software package, version 11.0 SE in all statistical analyses. In the first set of analyses, we analysed exposure to all deaths (nuclear and extended family) for all outcomes and adjusted for potential confounders. We undertook further analyses to examine whether the type of bereavement stress affected the risk of psychosis; in these, we restricted subsequent analyses to exposures in the nuclear family (death of parents or siblings of the index child). Where numbers allowed (for postnatal deaths only), we analysed effects of exposure by cause of death (suicide, injury or accident, or illness) and by exposure period, while controlling for previous exposure to a death in the prenatal period. Finally, we performed sensitivity analyses in which we calculated estimates after excluding offspring with multiple exposures across study periods. Only $0.5 \%$ of mothers in the study population were exposed to death in more than one study period (prenatal or postnatal period); as this is unlikely to make a difference to estimates, we did not exclude them from our analyses.

\section{Potential confounders}

All adjusted models included year of birth, sex of the offspring, maternal and paternal age ( $<20$ years, 20-24 years, 25-29 years (referent), 30-34 years, and $>34$ years) and nationality (Swedish or non-Swedish), parental socioeconomic status (maternal and paternal highest education: primary or lower secondary education of $\leq 9$ years, 10-12 years (referent), $>12$ years), and both parents without welfare (0 points) or at least one parent receiving welfare (1 point). We obtained information on parental socioeconomic status by linkage to the national censuses, which were performed every five years between 1960 and 1990, and by linkage to the income and taxation register. We also adjusted for urban birth (obtained by linkage to the medical birth register) in the index child (1=born in Stockholm, Malmo, or Gothenburg; $0=$ born other places) and history of any psychiatric illness in the family (ICD-10: F00-F99; ICD-9: 290-319; and ICD-8: 290-315). We excluded those with missing data on individual potential confounders, although missing numbers were small and only occurred in the following variables: urban birth $(n=3$, $>0.001 \%)$, education ( $\mathrm{n}=475,0.05 \%)$, receiving social allowance $(n=223,0.02 \%)$, and both parents born in Sweden $(n=56,0.01 \%)$ (table 1). Initially, we adjusted models for potential confounders one by one to assess the effects of individual factors. emigrated or died before age 20 years $(n=66$ 687) and those with unknown exposure status owing to missing linkage to either parent or any siblings $(n=8318)$, which left 1076878 potential participants. Further exclusions were made for missing data on gestational age $(n=3877)$, development of psychosis before age $10(n=136)$, and exposure between ages 13 and $20(n=27529)$, leaving 1045336 potential participants. Finally, we excluded those with missing linkage to grandparents ( $\mathrm{n}=98338$ ), which left a final analytical sample of 946994 . We used this sample for all analyses where grandparents' data were included (subsample 1).

For the subsidiary analysis examining associations only with exposures in the nuclear family (death of siblings and parents of index offspring), we used the original sample ( $n=1045336)$; this sample may have also included those with missing links to grandparents in both exposed and unexposed cases (subsample 2).

\section{Results}

During the study period, 321249 out of the 946994 (33.9\%) participants were exposed to death in the family before age 13 . Table 1 shows the percentages of cases of psychosis in the cohort overall. Of those exposed to any death during the study period, $1323(0.4 \%)$ developed a non-affective psychosis and $556(0.17 \%)$ an affective psychosis. Overall, 11117 people (1.2\%) were exposed to death from suicide and $15189(1.6 \%)$ to death from accidents, but most $(n=280172,29.6 \%)$, were exposed to deaths from natural causes. Table 1 shows the baseline characteristics of the cohort according to outcome.

\section{Risk after prenatal and postnatal exposure}

Overall, the risk of developing a psychotic illness after stress from a death in the family was marginally increased in any prenatal or postnatal period (crude odds ratio 1.24, 95\% confidence interval 1.17 to 1.32 ); this was slightly greater in the postnatal period (table $2 \Downarrow$ ). When the analysis was subdivided by antenatal period, no association was found between exposure to stress from a death in the family preconception or during any trimester and risk of psychosis; only postnatal exposure was significantly associated with an increased risk of psychosis.

Initially, we adjusted models for year of birth, sex, social class indicators and presence of siblings. These adjustments attenuated, but did not materially change estimates. Subsequently adding in to the model adjustments for either psychosis in the family or family history of any psychiatric illness made the greatest difference to estimates, but this was still moderate. Adding in other potential confounders (for example, urban birth, maternal and paternal age) did not substantially alter the results. Table 2 therefore shows adjusted models including all potential confounders in the adjusted estimates (adjusted odds ratio for any exposure and all psychoses $1.16,95 \%$ confidence interval 1.09 to1.23).

\section{Risk of non-affective and affective psychoses}

The pattern of risk for non-affective psychosis was similar to that for all psychoses; it was not significantly increased in any prenatal period and was strongest for the postnatal years, with the adjusted odds ratios ranging from 1.12 to 1.23 and $95 \%$ confidence intervals ranging between 1.02 and 1.38 . The risk of developing affective psychosis was marginally increased only after exposure to a death in the family in the period between 7 and 12.9 years (adjusted odds ratio 1.17, 1.02 to 1.34). Overall, 
risks were higher for non-affective psychosis when comparing with risks for affective psychosis.

\section{Risk after death in the nuclear family}

When we confined exposure to death in the nuclear family (siblings and parents of index offspring), there were not enough people exposed preconception or during fetal life who later developed psychosis to calculate risks separately for all antenatal periods (table $3 \Downarrow$ ). The risk of all psychosis was not significantly increased after exposure across the whole prenatal period (1.29, 0.82 to 2.02 ). During the postnatal period, an increased risk of all psychosis was associated with deaths in the nuclear family during all three childhood periods $(1.45,1.28$ to 1.65$)$. This excess risk occurred across diagnoses but was greatest for affective psychosis. Estimates increased the earlier in childhood the death occurred, although confidence intervals overlapped: for non-affective psychosis, the adjusted odds ratios from birth to 2.9 years was 1.82 (95\% confidence interval 1.33 to 2.47 ), from 3 to 6.9 years was 1.46 (1.12 to 1.90$)$, and from 7 to 12.9 years was 1.22 (1.00 to 1.50); and for affective psychosis from birth to 2.9 years was 2.28 ( 1.46 to 3.55 ), from 3 to 6.9 years was 1.75 (1.19 to 2.59$)$, and from 7-12.9 years was 1.68 (1.25 to 2.25$)$.

\section{Risk after accident or suicide compared with natural causes}

The literature suggests that the occurrence of suicide and, to some extent, accidents, is related to risk of psychiatric illness. ${ }^{28} 29$ A sudden unnatural cause of death could, of itself, be considered a marker of psychiatric illness in the family. ${ }^{24}{ }^{30} \mathrm{We}$, therefore, analysed outcomes after exposure in postnatal periods according to cause of death (table $4 \Downarrow$ ). Risk estimates associated with exposure to suicide were higher than those associated with exposure to deaths from accidents, which were in turn higher than risks associated with other natural causes of death: the crude odds ratio for all psychoses after suicide was 2.41 (95\% confidence interval 2.02 to 2.88 ), after accidents it was 1.30 (1.06 to 1.60), and after other cause deaths was 1.07 (1.01 to 1.14). Adjustments for psychiatric history in the family produced the greatest reduction in estimates for suicides compared with risks after either accidents or other causes of death (table 4). Other key confounders, including social class indicators, produced only a moderate further reduction in risk estimates. Thus, after suicide the fully adjusted odds ratio for all psychoses was 1.77 (95\% confidence intervals 1.47 to 2.13 ), for non-affective psychosis was 1.53 (1.22 to 1.91), and for affective psychosis was 2.52 (1.91 to 3.33). By contrast, the risks associated with other causes of death or deaths due to natural causes did not materially change following adjustment for family history or other potential confounders.

The largest risk estimates were generally seen in those exposed earliest in childhood (0-2.9 years), and risks tended to decrease as age at exposure increased. Overall, the risks were higher for affective psychosis and after suicide, than after accidental deaths, and became non-significant after other causes of death. Suicides were significantly more likely to occur in nuclear family members, who tended to be younger $(16.4 \%)$, than in extended family members, who tended to be older $(2.2 \%), \mathrm{P}<0.001$.

\section{Discussion}

We explored the risk of offspring developing psychosis after antenatal exposure of the mother to a severe psychosocial stressor from six months preconception and during fetal life, and after the death of a close family member during the postnatal period and throughout childhood to adolescence. There were three main findings. First, we found no evidence for an association between excess risk of any psychotic illness in offspring after maternal exposure to bereavement stress preconception or in any trimester. Restricting prenatal exposure to the stress of death in the nuclear family increased the risks, but the effects remained far from significant for prenatal exposure. Secondly, and in contrast with prenatal exposure, exposure to a death in the family during childhood through to adolescence was associated with a significantly increased risk of psychotic illness. This effect was most pronounced after a death in the nuclear family - that is, a parent (including mother) or sibling, compared with a death in the extended family - that is, a grandparent; effects were larger the earlier in childhood the death occurred. Thirdly, proportionally more suicides occurred in the nuclear family than in the extended family, in part because suicides occurred at younger ages. Excess risk was greatest in those who experienced suicide compared with a death caused by injury or an accident, which in turn produced a higher risk estimate than other natural causes of death, after which the association was weak. Risk of subsequent psychosis was higher after a suicide in the nuclear family in early childhood between birth and 3 years and, in particular, for affective psychosis.

\section{Comparison with previous studies}

Our data are broadly consistent with the largest population study to date of bereavement stress, ${ }^{22}$ where effects on schizophrenia, non-affective psychosis, and bipolar disorder were not seen after prenatal exposure. But our data are inconsistent with other population studies from Scandinavia. ${ }^{16} 20$ Evidence for an association between antenatal stress and schizophrenia is relatively weak. Paternal loss in the first but not second and third trimesters was reported to increase the risk of all psychiatric disorders compared with loss of fathers in the first year of an offspring's life, ${ }^{16}$ and to increase the risk of schizophrenia but only in those without a family history of psychiatric disorders. ${ }^{20}$ One of the Scandinavian studies ${ }^{21}$ also reported an excess risk of affective disorder, including bipolar disorder, after bereavement in the second trimester but not in the first or third trimesters, and only in men.

Most studies have generally not considered differences in risks associated with the stress of experiencing a death in a member of the nuclear family versus extended family, and none has detailed the effects of different causes of death, although some have considered the effect of parental suicide.$^{30}$ In our study, risk estimates were higher after death in the nuclear family than after death of any extended family member. Risks for non-affective psychosis were marginally greater than for affective psychosis, but only after the death of any extended family member. The reverse was true after the death of a nuclear family member, although numbers were too small to examine the effects of prenatal exposure to deaths in the nuclear family alone. The dose-response relation we report, where risks were generally higher after deaths in closer family members, and the earlier in childhood that the deaths occurred, and greatest after suicide, provide support for parental loss in childhood being a marker of both higher familial and higher environmental vulnerability to psychiatric disorder. Suicide increases the risk of psychiatric disorders through both genetic ${ }^{24} 3132$ and environmental effects. ${ }^{32-36}$ Parental loss, in particular from suicide, may have different meanings and consequences for offspring at different developmental stages. ${ }^{32}{ }^{34} \mathrm{~A}$ longstanding literature describes a range of poor short and longer term outcomes in children exposed early to parental loss. Higher risks were seen for exposure in younger ages after death in the 
nuclear family. We offer two non-mutually exclusive explanations. First, the higher risk could reflect a greater vulnerability of brain development in early childhood to adverse effects from children's environment and care. Secondly, the higher risk may reflect a greater duration of exposure to adverse social effects associated with the death of a close family member. A recent population survey of mental health among 5-16 year olds suggests that bereaved children are about one and a half times more likely than other children to have a diagnosis of any mental disorder. ${ }^{36}$ Two Danish register studies $^{29}{ }^{30}$ describe suicide of a mother being associated with a particularly increased risk of admission with bipolar disorder as an adult, especially if death occurs before the child is 10 years of age. ${ }^{30}$ Death of a relative by causes other than suicide was not associated with such an increased risk.

Mechanisms of risk, and indeed resilience for children living in families bereaved through the loss of a child or parent, are likely to be complex ${ }^{3135}$ and to include primarily social factors alongside individual differences in the resilience of the child or family involved. To date, studies have not been able to disentangle genetic susceptibility to mental illness or death in the nuclear family from social disadvantage and their interaction with bereavement in childhood. In this study, adjusting for most potential confounders, including indicators of socioeconomic status, such as receipt of welfare and parental education, made little difference to risk estimates. Only a family history of psychotic or other psychiatric illness materially reduced the risk estimates, especially from suicide, but also from death through injuries and accidents; it did not materially change estimates for deaths from other natural causes. Thus, the association is supported by genetic factors, ${ }^{25}{ }^{26}$ but as increased risks were still associated with both suicides and death from injuries or accidents, they may only explain a minor part of the crude excess risk.

\section{Strengths and limitations of this study}

This study has several methodological strengths. We describe rigorously the associations between exposures to bereavement stress in the preconception and prenatal periods and during childhood and risk for later psychiatric morbidity in offspring using a precise measurement of severe psychological stress at the individual level, validated measures of psychopathological outcomes, and adjustment for important child, family, and parental confounders. Several limitations remain relevant and should be dealt with in future research. For example, the death of a relative causes a subjective level of stress that varies by individual and circumstance and may endure over a variable length of time. Using date of death to time exposure to stress, we assume the relevant period of stress is the date of the death. We also assume that death of a relative induces substantial stress, whereas family members may not always grieve when someone dies-for example, if death occurs in an elderly relative or follows long term illness when it may provide relief-a notion with some support from our data, as cause of death determined the extent of risk. However, in general we believe that loss of a first degree relative (a partner or child) is very likely to result in grief and the associated psychological stress. Bereaved mothers might also modify relevant aspects of their behaviour (for example, substance misuse) in response to the stress, which may influence the associations. ${ }^{37}{ }^{38} \mathrm{We}$ were unable to assess accurate estimates for exposure to bereavement stress in the nuclear family by antenatal trimester or sex because events were too rare. Social class and socioeconomic status are well known associations of severe mental illness, such as schizophrenia, ${ }^{38} 39$ and loss of a parent is well recognised to bring socioeconomic disadvantage to a family. ${ }^{35}$ Although we adjusted for social class at birth of the child, we do not have a longitudinal measure of social class to take account of the effects of a decline in social circumstances associated with bereavement in families. Similarly, loss of a child has been associated with marital breakdown, ${ }^{37}$ and some evidence suggests that the children of bereaved parents may be more likely to live in single parent households, with their attendant excess risks associated with social adversity. ${ }^{35-39}$ We chose to rank exposures by timing of exposure to delineate critical periods of developmental risk. Overall, less than $0.5 \%$ of cases were exposed more than once, and sensitivity analysis found that unranking exposure made little difference to the results (data available from authors on request). We have previously scrutinised the level of misclassification when using inpatient care for psychosis as an indicator of occurrence of psychosis. During the 1980s in Sweden, there were no mobile outreach teams for psychoses, nor any specialist outpatient units. Thus, most incident cases of psychoses were treated in inpatient care. This gradually changed during the 1990s, and by 2005, 25\% of incident cases were treated in outpatient care. ${ }^{40}$ This proportion may have increased since then, but as the follow-up in this cohort was between 1973 and 2006, we believe that the misclassification is likely to be relatively small and of an acceptable magnitude.

Few studies have been able to look specifically at severe mental health outcomes of children growing up in bereaved families in a whole population, or to examine risk by cause of death. Our findings support previous studies of the sequelae of suicide ${ }^{29} 30^{32-34}$ but further suggest that those exposed to suicide early in childhood have the greatest excess risk of subsequent psychotic illness. Early postnatal development and neurodevelopment, especially in the prefrontal cortex,${ }^{41}$ may be particularly susceptible to diminished parenting resources, sensitivity, or stimulation as a consequence of maternal or parental stress. ${ }^{42}{ }^{43}$ However, these findings cannot be explained merely by confounding due to family psychiatric history, and the mechanisms of risk are likely to be complex..$^{25-27} 36$ There is a pressing need to identify resilience factors in children in bereaved families to develop appropriate interventions. ${ }^{44} 45$ Future studies should examine factors associated with resilience as an outcome alongside risk. ${ }^{44}$

\section{Potential implications of the study}

In this population, the lack of effect of severe prenatal maternal bereavement stress on the risk of psychosis in offspring has several possible implications. Taken together, the accumulated evidence is predominantly negative and overall suggests no consistent effect on risk of psychosis. This does not rule out other potential effects of prenatal bereavement. If this is the case, it suggests that severe psychological stress in pregnancy may be related to the social, emotional, and cognitive development of offspring, but without any detectable effect on risk of psychosis. Similarly, it is unclear why our results for bereavement stress and psychosis risk differ from those of studies examining prenatal stress and some other neuropsychiatric outcomes in offspring, such as attention-deficit/hyperactivity disorder or depression. ${ }^{72}$ One possible explanation is that a more severe disorder, such as psychosis, involves either alternative pathways or additional risk pathways. Exposure to several additional risk factors may be less likely to occur in a population where maternal health is good. Thus, severe antenatal maternal psychological stress may be an insufficient exposure in the pathway to more severe neurodevelopmental abnormalities such as psychosis, while remaining sufficient for more common, less severe 
neurodevelopmental outcomes. However, it may simply be that non-psychotic outcomes share only some of the risk mechanisms, or different risk mechanisms, to psychosis. We do not fully understand the mechanisms of risk and resilience in the human fetus, although the fetus may be relatively protected from fluctuations in some maternal environmental stressors ${ }^{43}$ through several fetoplacental mechanisms that protect the immature fetal brain against the effects of maternal stress. These include $\beta$ hydroxysteroid hydrogenase, an enzyme that breaks down maternal plasma glucocorticoids; as pregnancy progresses, increasing levels of maternal corticotrophin releasing hormone binding protein binds to maternal corticotrophin releasing hormone and inactivates it; and by mid-pregnancy, responses by the maternal hypothalamic-pituitary axis are attenuated or blunted. ${ }^{43} \mathrm{We}$ found that the strongest association for risk of psychosis occurred after death in the nuclear family in early childhood (birth to 3 years) and, as suggested, this may reflect greater vulnerability to abnormal brain developmental trajectories the earlier the exposure occurs. In addition, the earlier in childhood, the longer a child is likely to be exposed to disruptive social and family effects associated with, for example, parental loss. Although previous work on childhood trauma and psychosis has rarely included children as young as those included here (0-2.9 years), exposures such as neglect, abuse, and bullying are difficult to ascertain in preschool aged children. However, our results in middle childhood are consistent with increasing evidence that such trauma may be related to later risk of psychosis. $^{46}$

\section{Future directions}

Exposure to death of a parent or sibling in childhood is associated with an excess risk of developing a psychotic illness later in life. This does not seem to be the case after prenatal maternal exposure to death in the family. Risk is particularly associated with exposure in early childhood, or if death were by suicide or injury or accident compared with other causes of death. These associations are explained to some extent by genetic factors but are also likely, in large part, to include complex combinations of factors, creating more or less risk and resilience to future stressors. Such complex mechanisms require further investigation, and future studies should consider the broader contexts of parental suicide and parental loss in non-western, ethnically diverse populations and during conflict. More detailed evidence from adequately powered cohorts is also required before appropriately timed and appropriately resourced interventions can be developed to protect vulnerable families and children.

Contributors: $\mathrm{CD}, \mathrm{KMA}$, and LJ conceived the study and $\mathrm{HH}, \mathrm{JH}, \mathrm{ES}$, and $\mathrm{SW}$ helped with its development. LJ, KMA, and $\mathrm{HH}$ conducted the analysis. KMA, $\mathrm{CD}$, and $\mathrm{HH}$ wrote the first and subsequent drafts of the paper, with important intellectual input from the coauthors. All authors had full access to the data, specifically, the statistical reports and tables arising from the data, and take responsibility for the integrity of the data and accuracy of the data analysis. All authors have approved the final version of the manuscript submitted for publication. KMA and $C D$ act as guarantors.

Funding: KMA and $\mathrm{HH}$ were supported by a National Institutes of Health Research Capacity Funding small grant for travel to Sweden, and this grant also supported some costs of the data linkage. Other data linkage and staff costs in Sweden were supported by grants from the Swedish Research Council (CD) and Swedish Council for Working Life and Social Research (2003-0376). ES acknowledges support received as Lisa
Oehler, visiting professor, Department of Psychiatry, University of Göttingen, Germany.

Competing interests: All authors have completed the ICMJE form at www.icmje.org/coi_disclosure.pdf (available on request from the corresponding author) and declare that: all authors have support from their institutions (Universities of Manchester and Uppsala and the Karolinska Institutet) for the submitted work; have/had no relationships with companies that might have an interest in the submitted work in the previous three years; their spouses, partners, or children have no financial relationships that may be relevant to the submitted work; and have no non-financial interests that may be relevant to the submitted work.

Ethical approval: The study was approved by the regional ethical review board at Karolinska Institutet, Stockholm (No 01-100 together with 03-177 and 2005/1439-32).

Data sharing: No additional data available.

Transparency: KMA and CD affirm that the manuscript is an honest, accurate, and transparent account of the study being reported and that no important aspects of the study have been omitted.

Barker DJP. Mothers, babies and health in later life. Churchill Livingstone, 1998.

2 Mousseau TA, Fox CW. The adaptive significance of maternal effects. Trends Ecol Evol 1998;13:403-7.

3 Garcia-Moreno C. Intimate partner violence and fetal loss. Lancet 2009;373:278-9.

4 Beydoun H, Saftlas AF. Physical and mental health outcomes of prenatal maternal stress in human and animal studies: a review of recent evidence. Paediatr Perinat Epidemiol 2008;22:438-66.

5 Khashan AS, Mcnamee R, Abel KM, Mortensen PB, Kenny LC, Pedersen MG, et al. Rates of preterm birth following antenatal maternal exposure to severe life events: a population-based cohort study. Hum Reprod 2009;24:429-37.

6 Khashan AS, Mcnamee R, Abel KM, Pedersen MG, Webb RT, Kenny LC, et al. Reduced infant birthweight consequent upon maternal exposure to severe life events. Psychosom Med 2008;70:688-94.

7 Class QA, Lichtenstein P, Langstrom N, D'Onofrio BM. Timing of prenatal maternal severe life events and adverse pregnancy outcomes: a population study of 2.6 million pregnancies. Psychosom Med 2011;73:234-41.

8 Buss C, Davis EP, Muftuler LT, Head K, Sandman CA. High pregnancy anxiety during mid-gestation is associated with decreased gray matter density in 6-9-year-old children. Psychoneuroendocrinology 2010;35:141-53.

9 Buss C, Davis EP, Shahbaba B, Pruessner JC, Head K, Sandman CA. Maternal cortisol over the course of pregnancy and subsequent child amygdala and hippocampus volumes and affective problems. Proc Natl Acad Sci 2012;109:E1312-9.

10 King S, Laplante DP. The effects of prenatal maternal stress on children's cognitive development: Project Ice Storm. Stress 2005;8:35-45.

11 Meijer A. Child psychiatric sequelae of maternal war stress. Acta Psych Scand 1985;72:505-11.

12 Van Os J, Selten J-P. Prenatal exposure to maternal stress and subsequent schizophrenia The May 1940 invasion of The Netherlands. Br J Psychiatry 1998;172:324-6.

13 Selten J-P, Cantor-Graae E, Nahon D Levav I, Aleman A, Kahn RS. No relationship between risk of schizophrenia and prenatal exposure to stress during the Six-Day War or Yom Kippur War in Israel. Schizophr Res 2003;63:131-5.

14 Imamura $\mathrm{Y}$, Nakane $\mathrm{Y}$, Ohta $\mathrm{Y}$, Kondo $\mathrm{H}$. Life time prevalence of schizophrenia in individuals prenatally exposed to atomic bomb radiation in Nagasaki City. Acta Psych Scand 1999;100:344-9.

15 Selten J-P, Van der Graaf Y, Van Duursen R, Gispen-de-Wied CC, RS Kahn. Psychotic illness after prenatal exposure to the 1953 Dutch Flood Disaster. Schizophr Res 1999;5:243-5.

16 Huttunen MO, Niskanen P. Prenatal loss of father and psychiatric disorders. Arch Gen Psych 1978;35:429-31.

17 Myhrman A, Rantakallio P, Isohanni M, Jones P, Partanen U. Unwantedness of a pregnancy and schizophrenia in the child. Br J Psychiatry 1996;169:637-40.

18 Herman DB, Brown AS, Opler MS, Desai M, Malaspina D, Bresnahan M, et al. Does unwantedness of pregnancy predict schizophrenia in the offspring? Soc Psychiatry Psychiatr Epidemiol 2006;41:605-10.

19 Weinstock M. Alterations induced by gestational stress in brain morphology and behaviour of the offspring. Prog Neurobiol 2001;65:427-51.

20 Khashan A, Abel KM, McNamee R, Pedersen MG, Webb RT, Baker PN, et al. Higher risk of offspring schizophrenia following prenatal exposure to severe life events. Arch Gen Psychiatry 2008;65:146-52.

21 Khashan A, McNamee R, Henriksen TB, Pedersen MG, Kenny LC, Abel KM, et al. Risk of affective disorders following prenatal exposure to severe life events: a Danish population-based cohort study. J Psychiatr Res 2011:45:879-85.

22 Class Q, Abel KM, Khashan AS, Rickert ME, Dalman C, Larsson H, et al. Offspring psychopathology following preconception, prenatal, and postnatal maternal bereavement stress. Psychol Med 2013;17:1-14.

23 Luoma JB, Martin CE, Pearson JL. Contact with mental health and primary care providers before suicide: a review of the evidence. Am J Psychiatry 2002;159:909-16.

24 Tidemalm D, Runeson B, Waern M, Frisell T, Carlström E, Lichtenstein P, et al. Familial clustering of suicide risk: a total population study of 11.4 million individuals. Psychol Med 2011;41:2527-34.

25 Agid O, Shapira B, Zislin J, Ritsner M, Hanin B, Murad H, et al. Environment and vulnerability to major psychiatric illness: a case control study of early parental loss in major depression, bipolar disorder and schizophrenia. Mol Psychiatry 1999;4:163-72. 


\section{What is already known on this topic}

Severe psychological stress during the prenatal period and early life is considered a risk factor for severe mental illness in adulthood, but the evidence is inconclusive

The largest study to date shows no effect of antenatal maternal bereavement stress on severe mental health outcomes of offspring in adulthood, but it did not distinguish between exposures to loss of a close compared with more distant relative or between causes of death

The notion that antenatal or early life stress increases the risk of severe mental illness as an adult has important implications for the identification of children at risk

\section{What this study adds}

Severe antenatal maternal stress was not associated with an increased risk of later severe mental illness in offspring; loss of a parent or sibling in early childhood, especially after sudden death, was associated with an increased risk of psychosis

This increased risk was largely in children who had been bereaved by suicide of a parent before the age of 3 and was not explained by a family history of mental illness or suicide

Greater consideration should be given to the early environment of children exposed to parental loss, especially after, and protective measures should be considered for future evaluation in vulnerable families

26 Furukawa TA, Ogura A, Hirai T, Fujihara S, Kitamura T, Takahashi K. Early parental separation experiences among patients with bipolar disorder and major depression: a case-control study. J Affect Disord 1999;52:85-91.

27 Morgan C, Kirkbride JS, Leff J, Craig T, Hutchinson G, McKenzie K, et al. Parental separation, loss and psychosis in different ethnic groups: a case-control study. Psychol Med 2006;37:495-503

28 Crump C, Sundquist K, Winkleby MA, Sundquist J. Mental disorders and risk of accidental death. Br J Psychiatry 2013;203:297-302.

29 Kessing LV, Agerbo E, Mortensen PB Major stressful life events and other risk factors for first admission with mania. Bipolar Disord 2004:6:122-129.

30 Tsuchiya KJ, Agerbo E, Mortensen PB. Parental death and bipolar disorder: a robust association was found in early maternal suicide. J Affect Disord 2005;86:151-9.

31 Mortensen PB, Pedersen $\mathrm{CB}$, Melbye M, Mors $\mathrm{O}$, Ewald $\mathrm{H}$. Individual and familial risk factors for bipolar affective disorder. Arch Gen Psychiatry 2003;60:1209-15.

32 Kuramoto SJ, Runeson B, Stuart EA, Lichtenstein P, Wilcox HC. Time to hospitalization for suicide attempt by the timing of parental suicide during offspring early development. JAMA Psychiatry 2013;70:149-57.

33 Wilcox HC, Kuramoto SJ, Lichtenstein P, Långström N, Brent DA, Runeson B. Psychiatric morbidity, violent crime, and suicide among children and adolescents exposed to parental death. J Am Acad Child Adolesc Psychiatry 2010;49:514-23.

34 Conwell Y, Duberstein PR, Cox C, Herrmann JH, Forbes NT, Caine ED. Relationships of age and axis I diagnoses in victims of completed suicide: a psychological autopsy study. Am J Psychiatry 1996;153:1001-8.

35 Maier EH, Lachman ME. The consequences of early parental loss and separation for health and well-being in midlife. Int J Behav Develop 2000;24:183-9.

36 Parsons S. Long-term impact of childhood bereavement: preliminary analysis of the 1970 British Cohort Study (BCS70). 2011. www.education.gov.uk/publications/ OrderingDownload/LongTermOutcomesOfParentalBereavement pdf

37 Rogers $\mathrm{CH}$, Floyd FJ, Seltzer MM, Greenberg J, Hong J. Long term effects of the death of a child on parents' adjustment in midlife. J Fam Psychol 2008;22:203-11.

38 Wicks S, Hjern A, Gunnel D, Lewis G, Dalman C. Social adversity in childhood and the risk of developing psychosis: a national cohort study. Am J Psychiatry 2005;162:1652-7.
39 Cantor-Graae E. The contribution of social factors to the development of schizophrenia: a review of recent findings. Can J Psychiatry 2007;52:277-86.

40 Jorgensen L, Ahlbom A, Allebeck P, Dalman C. The Stockholm non-affective psychoses study (snaps): the importance of including out-patient data in incidence studies. Acta Psych Scand 2010;121:389-92.

41 Liu J, Dietz K, Deloyht JM, Pedre X, Kelkar D, Kaur J, et al. Impaired adult myelination in the prefrontal cortex of socially isolated mice. Nat Neurosci 2012;15:1621-3.

42 Fish EW, Shahrokh D, Bagot R, Caldji C, Bredy T, Szyf M, et al. Epigenetic programming of stress responses through variations in maternal care. Ann NY Acad Sci 2004; 1036:167-80.

43 Del Guidice M. Fetal programming by maternal stress: insights from a conflict perspective. Psychoneuroendocrinology 2012;37:1614-29

44 Lin KK, Sandler IN, Ayers TS, Wolchik SA, Luecken LJ. Resilience in parentally bereaved children and adolescents seeking preventive services. J Clin Child Adolesc Psychol 2004;33:673-83.

45 Fauth B, Thompson M, Penny A. Associations between childhood bereavement and children's background, experiences and outcomes. Secondary analysis of the 2004 Mental Health of Children and Young People in Great Britain. National Children's Bureau, 2009. 46 Susser E, Widom CS. Still searching for lost truths about the bitter sorrows of childhood. Schizophr Bull 2012:38:672-5.

Accepted: 16 December 2013

\section{Cite this as: BMJ 2014;348:f7679}

This is an Open Access article distributed in accordance with the Creative Commons Attribution Non Commercial (CC BY-NC 3.0) license, which permits others to distribute, remix, adapt, build upon this work non-commercially, and license their derivative works on different terms, provided the original work is properly cited and the use is non-commercial. See: http://creativecommons.org/licenses/by-nc/3.0/. 


\section{Tables}

Table 1 | Characteristics of subsample 1 ( $n=946$ 994), by outcome

\begin{tabular}{|c|c|c|c|c|}
\hline \multirow[t]{2}{*}{ Characteristics } & \multicolumn{4}{|c|}{ No $(\%)$ of participants } \\
\hline & No psychoses $(n=942559)$ & All psychoses $(n=4435)$ & $\begin{array}{l}\text { Non-affective psychosis } \\
\qquad(\mathrm{n}=3366)\end{array}$ & Affective psychosis ( $n=1448$ ) \\
\hline \multicolumn{5}{|l|}{ Index person } \\
\hline Women & $457170(48.5)$ & $2032(45.8)$ & $1396(41.5)$ & $840(58.0)$ \\
\hline Urban birth & 123877 (13.1) & $730(16.5)$ & $568(16.9)$ & $220(15.2)$ \\
\hline Sibling & $800653(84.9)$ & $3441(77.6)$ & $2579(76.6)$ & $1161(80.2)$ \\
\hline \multicolumn{5}{|l|}{ Parents } \\
\hline \multicolumn{5}{|l|}{ Education (years): } \\
\hline$\leq 9$ & $98234(10.4)$ & $522(11.8)$ & $404(12.0)$ & $165(11.4)$ \\
\hline $10-12$ & $468628(49.7)$ & $2024(45.6)$ & $1541(45.8)$ & $644(44.5)$ \\
\hline$\geq 12$ & 375234 (39.8) & $1877(42.3)$ & $1410(41.9)$ & $637(44.0)$ \\
\hline Receiving social allowance & $74558(7.9)$ & $713(16.1)$ & $571(17.0)$ & $186(12.8)$ \\
\hline Both parents born in Sweden & $867629(92.1)$ & $3895(87.8)$ & $2942(87.4)$ & $1289(89.0)$ \\
\hline \multicolumn{5}{|l|}{ Maternal age (years): } \\
\hline$<20$ & $46408(4.9)$ & $291(6.6)$ & $224(6.7)$ & $92(6.4)$ \\
\hline $20-24$ & $260897(27.7)$ & $1181(26.6)$ & $903(26.8)$ & $369(25.5)$ \\
\hline $25-29$ & $358615(38.0)$ & $1565(35.3)$ & $1160(34.5)$ & $529(36.5)$ \\
\hline $30-34$ & $205465(21.8)$ & $995(22.4)$ & $768(22.8)$ & $328(22.7)$ \\
\hline$>34$ & $71174(7.6)$ & $403(9.1)$ & $311(9.2)$ & $130(9.0)$ \\
\hline \multicolumn{5}{|l|}{ Paternal age (years): } \\
\hline$<20$ & $9112(1.0)$ & $59(1.3)$ & $46(1.4)$ & $17(1.2)$ \\
\hline $20-24$ & $141752(15.0)$ & $674(15.2)$ & $518(15.4)$ & $204(14.1)$ \\
\hline $25-29$ & 346466 (36.8) & $1510(34.0)$ & $1134(33.7)$ & $499(34.5)$ \\
\hline $30-34$ & $282909(30.0)$ & $1306(29.4)$ & $979(29.1)$ & $444(30.7)$ \\
\hline$>34$ & $162320(17.2)$ & $886(20.0)$ & $689(20.5)$ & $284(19.6)$ \\
\hline $\begin{array}{l}\text { Family history of psychiatric } \\
\text { illness }\end{array}$ & $172450(18.3)$ & $1782(40.2)$ & $1357(40.3)$ & $585(40.4)$ \\
\hline
\end{tabular}

Missing data for confounders for subsample 1 ( $n=946994)$ : urban birth $(n=3,>0.001 \%)$; education $(n=475,0.05 \%)$; receiving social allowance $(n=223,0.02 \%)$, and both parents born in Sweden $(n=56,0.01 \%)$. 
Table 2| Crude and adjusted odds ratios for risk of psychoses after exposure to bereavement stress during prenatal and postnatal periods ( $n=946$ 994). Total exposed $n=321249$; total unexposed $n=625745$

\begin{tabular}{|c|c|c|c|}
\hline Psychoses by exposure status & No of cases & Crude odds ratio $(95 \% \mathrm{Cl})$ & Adjusted odds ratio* $(95 \% \mathrm{Cl})$ \\
\hline \multicolumn{4}{|l|}{ All psychoses: } \\
\hline Unexposed & 2710 & 1 (Reference) $\dagger$ & - \\
\hline Any time & 1725 & 1.24 (1.17 to 1.32$)$ & $1.16(1.09$ to 1.23$)$ \\
\hline Any prenatal & 115 & $1.17(0.97$ to 1.41$)$ & 1.10 (0.91 to 1.32$)$ \\
\hline Any postnatal & 1610 & $1.25(1.17$ to 1.33$)$ & 1.16 (1.09 to 1.24$)$ \\
\hline Preconception & 58 & $1.32(1.02$ to 1.71$)$ & 1.24 (0.96 to 1.62$)$ \\
\hline First trimester & 16 & $1.03(0.63$ to 1.68$)$ & 0.95 (0.58 to 1.56$)$ \\
\hline Second trimester & 14 & 0.85 (0.50 to 1.44$)$ & 0.79 (0.46 to 1.33$)$ \\
\hline Third trimester & 27 & $1.22(0.84$ to 1.79$)$ & 1.14 (0.78 to 1.66$)$ \\
\hline $0-2.9$ years & 312 & $1.26(1.12$ to 1.42$)$ & $1.17(1.04$ to 1.32$)$ \\
\hline 3-6.9 years & 491 & 1.30 (1.18 to 1.43$)$ & 1.21 (1.09 to 1.33$)$ \\
\hline $7-12.9$ years & 807 & $1.21(1.12$ to 1.31$)$ & $1.13(1.04$ to 1.23$)$ \\
\hline \multicolumn{4}{|l|}{ Non-affective psychosis: } \\
\hline Unexposed & 2043 & 1 (Reference) & - \\
\hline Any time & 1323 & 1.26 (1.18 to 1.35$)$ & $1.17(1.09$ to 1.25$)$ \\
\hline Any prenatal & 92 & $1.25(1.01$ to 1.54$)$ & 1.15 (0.94 to 1.43$)$ \\
\hline Any postnatal & 1231 & $1.26(1.18$ to 1.36$)$ & $1.17(1.08$ to 1.26$)$ \\
\hline Preconception & 46 & $1.39(1.04$ to 1.86$)$ & $1.30(0.97$ to 1.74$)$ \\
\hline First trimester & 15 & $1.28(0.77$ to 2.13$)$ & $1.18(0.71$ to 1.96$)$ \\
\hline Second trimester & 12 & $0.97(0.55$ to 1.71$)$ & $0.89(0.50$ to 1.57$)$ \\
\hline Third trimester & 19 & $1.14(0.73$ to 1.79$)$ & 1.05 (0.67 to 1.66$)$ \\
\hline $0-2.9$ years & 242 & $1.30(1.14$ to 1.49$)$ & $1.19(1.04$ to 1.37$)$ \\
\hline $3-6.9$ years & 381 & $1.33(1.19$ to 1.49$)$ & $1.23(1.10$ to 1.38$)$ \\
\hline $7-12.9$ years & 608 & 1.21 (1.11 to 1.33 ) & $1.12(1.02$ to 1.23$)$ \\
\hline \multicolumn{4}{|l|}{ Affective psychosis: } \\
\hline Unexposed & 892 & 1 (Reference) & 1 (Reference) \\
\hline Any time & 556 & 1.21 (1.09 to 1.35$)$ & $1.14(1.02$ to 1.27$)$ \\
\hline Any prenatal & 33 & $1.02(0.72$ to 1.45$)$ & 0.96 (0.67 to 1.35$)$ \\
\hline Any postnatal & 523 & $1.23(1.10$ to 1.37$)$ & 1.15 (1.03 to 1.29$)$ \\
\hline Preconception & 15 & 1.04 (0.62 to 1.73$)$ & 0.98 (0.58 to 1.63$)$ \\
\hline First trimester & - & - & - \\
\hline Second trimester & - & - & - \\
\hline Third trimester & 11 & 1.51 (0.83 to 2.75$)$ & $1.41(0.77$ to 2.56$)$ \\
\hline $0-2.9$ years & 94 & $1.16(0.93$ to 1.43$)$ & 1.08 (0.87 to 1.34$)$ \\
\hline $3-6.9$ years & 156 & $1.25(1.05$ to 1.48$)$ & $1.17(0.99$ to 1.39$)$ \\
\hline $7-12.9$ years & 273 & 1.24 (1.09 to 1.42$)$ & $1.17(1.02$ to 1.34$)$ \\
\hline
\end{tabular}

*Generated by logistic regression; adjusted for sex, year of birth, country of birth, presence or absence of siblings, any family psychiatric history, urban birth, highest education of parents, receipt of welfare, and maternal and paternal age.

†General population reference group (people without the diagnosis being considered). 
Table 3 Crude and adjusted odds ratios for risk of psychosis after exposure to death in nuclear family during prenatal and postnatal periods ( $n=1045336$ ). Total exposed $n=31$ 535; total unexposed $n=1013801$

\section{Psychoses by exposure status}

All psychoses:

\begin{tabular}{|c|c|c|c|}
\hline Unexposed & 4879 & 1 (Reference) & - \\
\hline Any time & 282 & 1.87 (1. 65 to 2.10$)$ & 1.44 (1.27 to 1.63$)$ \\
\hline Any prenatal & 19 & 1.38 (0.88 to 2.18 ) & 1.29 (0.82 to 2.02$)$ \\
\hline Any postnatal & 263 & 1.91 (1.69 to 2.17 ) & 1.45 (1.28 to 1.65$)$ \\
\hline Preconception & 12 & $1.10(0.62$ to 1.93$)$ & 1.05 (0.59 to 1.85$)$ \\
\hline First trimester & - & - & - \\
\hline Second trimester & 一 & - & - \\
\hline Third trimester & - & - & - \\
\hline $0-2.9$ years & 56 & 2.26 (1.73 to 2.94$)$ & 1.84 (1.41 to 2.41$)$ \\
\hline $3-6.9$ years & 76 & 1.86 (1.48 to .234) & $1.47(1.16$ to 1.85$)$ \\
\hline $7-12.9$ years & 131 & 1.83 (1.53 to 2.17$)$ & 1.32 (1.10 to 1.58$)$ \\
\hline \multicolumn{4}{|c|}{ Non-affective psychosis: } \\
\hline Unexposed & 3763 & 1 (Reference) & - \\
\hline Any time & 212 & 1.82 (1.58 to 2.09$)$ & 1.36 (1.18 to 1.57$)$ \\
\hline Any prenatal & 15 & 1.42 (0.85 to 2.36$)$ & 1.30 (0.78 to 2.17$)$ \\
\hline Any postnatal & 197 & 1.86 (1.61 to 2.14$)$ & 1.36 (1.17 to 1.58$)$ \\
\hline Preconception & 10 & 1.18 (0.64 to 2.20$)$ & $1.13(0.61$ to 2.10$)$ \\
\hline First trimester & - & - & 一 \\
\hline Second trimester & - & 一 & - \\
\hline Third trimester & - & - & 一 \\
\hline $0-2.9$ years & 43 & 2.25 (1.66 to 3.04 ) & 1.82 (1.33 to 2.47 ) \\
\hline $3-6.9$ years & 58 & 1.84 (1.42 to 2.39$)$ & $1.46(1.12$ to 1.90$)$ \\
\hline $7-12.9$ years & 96 & 1.73 (1.41 to 2.12 ) & $1.22(1.00$ to 1.50$)$ \\
\hline \multicolumn{4}{|l|}{ Affective psychosis: } \\
\hline Unexposed & 1521 & 1 (Reference) & 1 (Reference) \\
\hline Any time & 102 & 2.16 (1.77 to 2.64$)$ & 1.80 (1.47 to 2.21$)$ \\
\hline Any prenatal & 8 & 1.87 (0.93 to 3.75$)$ & 1.77 (0.88 to 3.55$)$ \\
\hline Any postnatal & 94 & 2.19 (1.78 to 2.70$)$ & 1.80 (1.46 to 2.23$)$ \\
\hline Preconception & 5 & 1.46 (0.61 to 3.53$)$ & 1.40 (0.58 to 3.38$)$ \\
\hline First trimester & 0 & - & - \\
\hline Second trimester & - & - & - \\
\hline Third trimester & 一 & - & - \\
\hline $0-2.9$ years & 20 & 2.58 (1.66 to 4.01$)$ & 2.28 (1.46 to 3.55$)$ \\
\hline $3-6.9$ years & 26 & 2.04 (1.38 to 3.00$)$ & 1.75 (1.19 to 2.59$)$ \\
\hline $7-12.9$ years & 48 & 2.14 (1.61 to 2.85$)$ & 1.68 (1.25 to 2.25$)$ \\
\hline
\end{tabular}

*Generated by logistic regression; adjusted for sex, year of birth, country of birth, presence or absence of siblings, any psychiatric illness in family, urban birth, highest education of parents, receipt of welfare, and maternal and paternal age.

†General population reference group (people without the diagnosis being considered). 
Table 4| Crude and adjusted odds ratios for postnatal cause of death exposures and psychosis ( $n=1045336$ )

\begin{tabular}{|c|c|c|c|c|}
\hline Exposures & No of cases & Crude odds ratio (95\% $\mathrm{Cl})$ & Adjusted odds ratio* $(95 \% \mathrm{Cl})$ & Adjusted odds ratio† $(95 \% \mathrm{Cl})$ \\
\hline \multicolumn{5}{|l|}{ All psychoses } \\
\hline Any suicide & 127 & 2.41 (2.02 to 2.88$)$ & 1.85 (1.54 to 2.21$)$ & 1.77 (1.47 to 2.13$)$ \\
\hline Any accident & 95 & 1.30 (1.06 to 1.60$)$ & $1.19(0.97$ to 1.46$)$ & $1.18(0.96$ to 1.46$)$ \\
\hline Any other death & 1428 & $1.07(1.01$ to 1.14$)$ & $1.07(1.01$ to 1.14$)$ & $1.08(1.02$ to 1.15$)$ \\
\hline \multicolumn{5}{|l|}{ Suicide: } \\
\hline $0-2.9$ years & 33 & 2.84 (2.01 to 4.01$)$ & $2.29(1.62$ to 3.23$)$ & 2.17 (1.52 to 3.08$)$ \\
\hline $3-6.9$ years & 37 & 2.19 (1.58 to 3.03$)$ & $1.70(1.23$ to 2.35$)$ & 1.69 (1.22 to 2.36$)$ \\
\hline $7-12.9$ years & 59 & $2.32(1.80$ to 3.01$)$ & $1.73(1.33$ to 2.24$)$ & $1.63(1.25$ to 2.13$)$ \\
\hline \multicolumn{5}{|l|}{ Fatal injury or accident: } \\
\hline $0-2.9$ years & 30 & 2.10 (1.47 to 3.02$)$ & 1.93 (1.35 to 2.78$)$ & 1.86 (1.30 to 2.67$)$ \\
\hline $3-6.9$ years & 29 & 1.39 (0.96 to 2.00$)$ & $1.26(0.87$ to 1.82$)$ & 1.28 (0.89 to 1.84$)$ \\
\hline $7-12.9$ years & 36 & $0.92(0.66$ to 1.28$)$ & $0.84(0.60$ to 1.17$)$ & $0.83(0.59$ to 1.16$)$ \\
\hline \multicolumn{5}{|l|}{ Other death: } \\
\hline Birth- 2.9 years & 256 & 0.99 (0.87 to 1.13$)$ & 0.99 (0.87 to 1.12$)$ & 1.00 (0.88 to 1.13$)$ \\
\hline $3-6.9$ years & 468 & $1.13(1.02$ to 1.24$)$ & $1.12(1.02$ to 1.24$)$ & $1.13(1.02$ to 1.24$)$ \\
\hline $7-12.9$ years & 835 & $1.05(0.98$ to 1.14$)$ & 1.05 (0.97 to 1.13$)$ & 1.05 (0.98 to 1.14$)$ \\
\hline \multicolumn{5}{|l|}{ Non-affective psychosis } \\
\hline Any suicide & 87 & 2.14 (1.72 to 2.65$)$ & 1.63 (1.31 to 2.02$)$ & $1.53(1.22$ to 1.91$)$ \\
\hline Any fatal injury/accident & 72 & $1.28(1.01$ to 1.62$)$ & $1.17(0.92$ to 1.48$)$ & $1.16(0.91$ to 1.47$)$ \\
\hline Any other death & 1106 & $1.08(1.01$ to 1.16$)$ & $1.07(1.00$ to 1.15$)$ & 1.09 (1.02 to 1.17$)$ \\
\hline \multicolumn{5}{|l|}{ Suicide: } \\
\hline $0-2.9$ years & 21 & 2.34 (1.52 to 3.61$)$ & 1.88 (1.22 to 2.89$)$ & 1.73 (1.11 to 2.70$)$ \\
\hline 3-6.9 year & 28 & 2.15 (1.48 to 3.12$)$ & 1.66 (1.14 to 2.42$)$ & $1.63(1.12$ to 2.39$)$ \\
\hline 7-12.9 year & 38 & 1.93 (1.40 to 2.66$)$ & $1.43(1.04$ to 1.97$)$ & $1.31(0.93$ to 1.83$)$ \\
\hline \multicolumn{5}{|l|}{ Fatal injury or accident: } \\
\hline $0-2.9$ years & 20 & $1.82(1.17$ to 2.83$)$ & $1.67(1.07$ to 2.60$)$ & 1.59 (1.02 to 2.47$)$ \\
\hline $3-6.9$ years & 22 & 1.36 (0.90 to 2.08$)$ & $1.24(0.81$ to 1.89$)$ & $1.25(0.82$ to 1.91$)$ \\
\hline $7-12.9$ years & 30 & 0.99 (0.69 to 1.42$)$ & 0.91 (0.63 to 1.30$)$ & $0.89(0.62$ to 1.29$)$ \\
\hline \multicolumn{5}{|l|}{ Other death: } \\
\hline Birth-2.9 years & 207 & $1.04(0.90$ to 1.20$)$ & $1.04(0.90$ to 1.19$)$ & $1.05(0.91$ to 1.21$)$ \\
\hline 3-6.9 years & 366 & $1.14(1.03$ to 1.27$)$ & $1.14(1.02$ to 1.27$)$ & $1.15(1.03$ to 1.28$)$ \\
\hline 7-12.9 years & 635 & 1.04 (0.95 to 1.13$)$ & $1.03(0.94$ to 1.12$)$ & 1.04 (0.95 to 1.13$)$ \\
\hline \multicolumn{5}{|l|}{ Affective psychosis } \\
\hline Any suicide & 54 & 3.29 (2.50 to 4.33 ) & 2.52 (1.92 to 3.32 ) & 2.52 (1.91 to 3.33$)$ \\
\hline Any accident & 32 & $1.40(0.98$ to 1.99$)$ & $1.28(0.90$ to 1.82$)$ & $1.26(0.88$ to 1.80$)$ \\
\hline Any other death & 448 & $1.09(0.97$ to 1.21$)$ & $1.08(0.97$ to 1.21$)$ & 1.07 (0.95 to 1.19$)$ \\
\hline \multicolumn{5}{|l|}{ Suicide: } \\
\hline $0-2.9$ year & 15 & 4.07 (2.44 to 6.78 ) & 3.28 (1.97 to 5.47$)$ & 3.33 (2.00 to 5.56 ) \\
\hline $3-6.9$ years & 12 & 2.25 (1.28 to 3.98$)$ & 1.75 (0.99 to 3.10$)$ & 1.84 (1.04 to 3.25$)$ \\
\hline $7-12.9$ years & 29 & 3.68 (2.54 to 5.32 ) & 2.74 (1.89 to 3.97$)$ & 2.68 (1.84 to 3.92$)$ \\
\hline \multicolumn{5}{|l|}{ Fatal injury or accident: } \\
\hline $0-2.9$ years & 12 & 2.66 (1.50 to 4.70$)$ & 2.44 (1.38 to 4.32$)$ & 2.43 (1.38 to 4.30$)$ \\
\hline $3-6.9$ years & 10 & $1.53(0.82$ to 2.84$)$ & 1.39 (0.74 to 2.59$)$ & 1.43 (0.77 to 2.67$)$ \\
\hline 7-12.9 years & 10 & $0.82(0.44$ to 1.52$)$ & 0.75 (0.40 to 1.39$)$ & 0.69 (0.36 to 1.33$)$ \\
\hline \multicolumn{5}{|l|}{ Other death: } \\
\hline Birth-2.9 years & 69 & 0.85 (0.67 to 1.08$)$ & 0.85 (0.67 to 1.08$)$ & 0.84 (0.66 to 1.07$)$ \\
\hline $3-6.9$ years & 149 & $1.15(0.97$ to 1.36$)$ & $1.15(0.97$ to 1.36$)$ & $1.13(0.95$ to 1.34$)$ \\
\hline $7-12.9$ years & 274 & $1.12(0.98$ to 1.27$)$ & 1.11 (0.97 to 1.27$)$ & $1.10(0.96$ to 1.25$)$ \\
\hline
\end{tabular}




\section{Table 4 (continued)}

*Adjusted for psychiatric history in family (parents or siblings).

†Adjusted for psychiatric history in family (parents or siblings), siblings or not, sex and year of birth, country of birth, maternal and paternal age, urban birth, education of parents, and parental receipt of social allowance.

Reference group: unexposed to death, suicide attempt, accident, or serious illness of parent or siblings before age of 20 . Reference group is same in all analyses. 


\section{Figure}

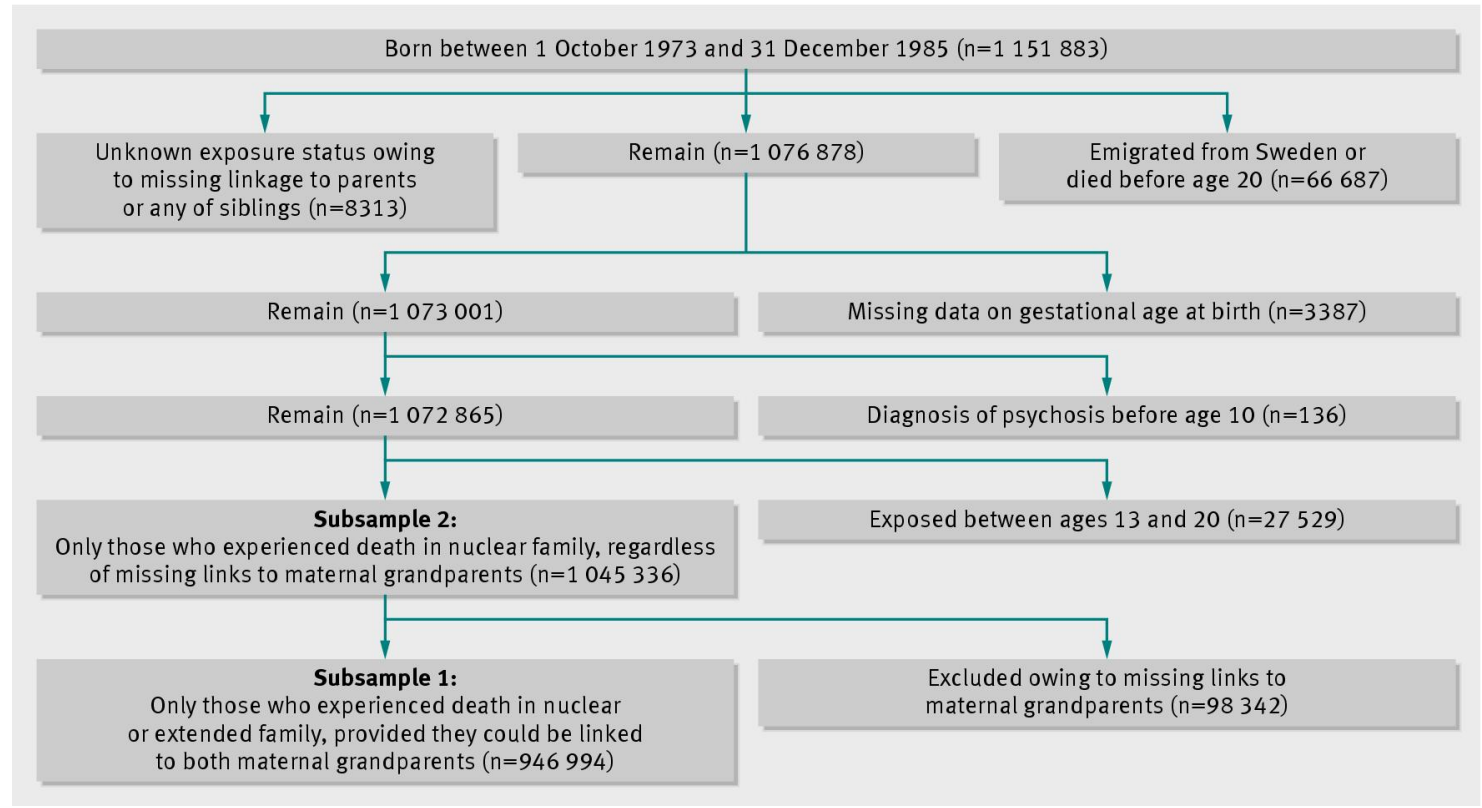

\section{Sample selection process}

